\section{Cutavirus in Cutaneous Malignant Melanoma}

\section{Sarah Mollerup, Helena Fridholm, Lasse Vinner, Kristín Rós Kjartansdóttir, Jens Friis-Nielsen, Maria Asplund, Jose A.R. Herrera, Torben Steiniche, Tobias Mourier, Søren Brunak, Eske Willerslev, Jose M.G. Izarzugaza, Anders J. Hansen, ${ }^{1}$ Lars P. Nielsen ${ }^{1}$}

Author affiliations: University of Copenhagen, Copenhagen, Denmark (S. Mollerup, H. Fridholm, L. Vinner, K.R. Kjartansdóttir, M. Asplund, T. Mourier, S. Brunak, E. Willerslev, A.J. Hansen); Technical University of Denmark, Kongens Lyngby, Denmark (J. Friis-Nielsen, J.A.R. Herrera, S. Brunak, J.M.G. Izarzugaza); Aarhus University, Aarhus, Denmark (T. Steiniche); Statens Serum Institut, Copenhagen (L.P. Nielsen), Aalborg University, Aalborg, Denmark (L.P. Nielsen)

DOI: http://dx.doi.org/10.3201/eid2302.161564

A novel human protoparvovirus related to human bufavirus and preliminarily named cutavirus has been discovered. We detected cutavirus in a sample of cutaneous malignant melanoma by using viral enrichment and high-throughput sequencing. The role of cutaviruses in cutaneous cancers remains to be investigated.

$\mathrm{P}_{\mathrm{a}}$ arvoviruses are small nonenveloped DNA viruses with a single-stranded linear genome of $\approx 5 \mathrm{~kb}$. In 2016, a novel species within the Protoparvovirus genus was discovered in fecal samples from children with diarrhea in Brazil and subsequently detected in samples of mycosis fungoides lesions (cutaneous T-cell lymphoma) of patients in France (1). This virus, provisionally named cutavirus, shows highest identity to the human bufaviruses of the Primate protoparvovirus 1 species. Bufaviruses are found in human fecal samples in low percentages (2-7). Using viral enrichment methods, we detected a cutavirus strain in an additional type of cancer, cutaneous malignant melanoma, further expanding the range of tissue types harboring cutaviruses and adding to the knowledge of the human virome.

We subjected a clinical sample of a cutaneous malignant melanoma lesion from a patient in Denmark to enrichment of virion-associated nucleic acids and enrichment of circular DNA molecules, followed by high-throughput sequencing (online Technical Appendix, http://wwwnc.cdc.gov/ EID/article/23/2/16-1564-Techapp1.pdf). BLASTn (https:// blast.ncbi.nlm.nih.gov/Blast.cgi?CMD=Web\&PAGE TYPE $=$ BlastDocs\&DOC_TYPE $=$ Download) analysis originally identified contigs related to human bufaviruses in de

${ }^{1}$ These authors contributed equally to this article. novo assembled contigs from both datasets. In light of the recently published cutavirus genomes (1), we compared these sequences with the cutaviruses and found high similarity to the cutaviruses. From overlapping contigs, we obtained the 4,452 bp (from start nonstructural protein 1 [NS1] to end viral protein 1 [VP1]) near-complete genome of a novel cutavirus strain, CutaV CGG5-268 (GenBank accession no. KX685945). Similar to the other cutavirus genomes, CutaV CGG5-268 included NS1 and VP1 open reading frames (ORFs) encoding proteins of 659 aa and 707 aa, respectively. The CutaV CGG5-268 sequence also contained the small putative 333-nt middle ORF, starting at position 2021, and a 270-nt ORF located within the VP2 coding region, starting at position 2768. Further testing is required to determine whether these ORFs encode proteins.

We performed phylogenetic analysis based on the NS1 and VP1 amino acid sequences (Figure). Because 4 of the 7 published cutavirus genomes contain partial NS1 sequences, we included only 3 cutavirus strains in the phylogenetic analysis of NS1. NS1-based analysis placed CutaV CGG5-268 closest to CutaV FR-F identified in a mycosis fungoides patient in France, whereas VP1-based analysis placed CutaV CGG5-268 closest to CutaV BR-450 identified in the feces of a child in Brazil.

Cutaviruses were discovered in human fecal samples by use of metagenomics and subsequently detected in 4 of 17 samples of mycosis fungoides lesions; however, 21 skin samples, including samples from skin cancers and parapsoriasis lesions, tested negative for cutavirus (1). Our discovery of cutavirus in a sample of cutaneous malignant melanoma shows that extraenteric presence of cutaviruses is not limited to skin infiltrated by neoplastic $\mathrm{T}$ cells. The detection of cutaviral DNA after virion enrichment may indicate viral replication taking place in the affected tissue. Human bufaviruses have so far been detected only in fecal samples, predominantly from patients having diarrhea or gastroenteritis, and in only $0.27 \%-4 \%$ of samples (2-8). Another virus of the Parvoviridae family, human parvovirus $\mathrm{B} 19$, is shown to persist in multiple tissue types, in most cases without an established correlation to disease (9). Animal protoparvoviruses have also been detected in several sample types, as discussed elsewhere (1). Thus, future studies may reveal an expanded range of tissue types harboring cutaviruses. So far, cutaviruses have only been detected in the tissues investigated, and their direct involvement in disease has not been established. One limitation of this study is the lack of healthy controls for assessing whether cutavirus can also be detected in healthy skin. Furthermore, screening of a larger number of samples is necessary to determine the prevalence of cutavirus in malignant melanoma.

In 9 additional melanoma samples investigated in our laboratory, we did not identify contigs with similarity to 


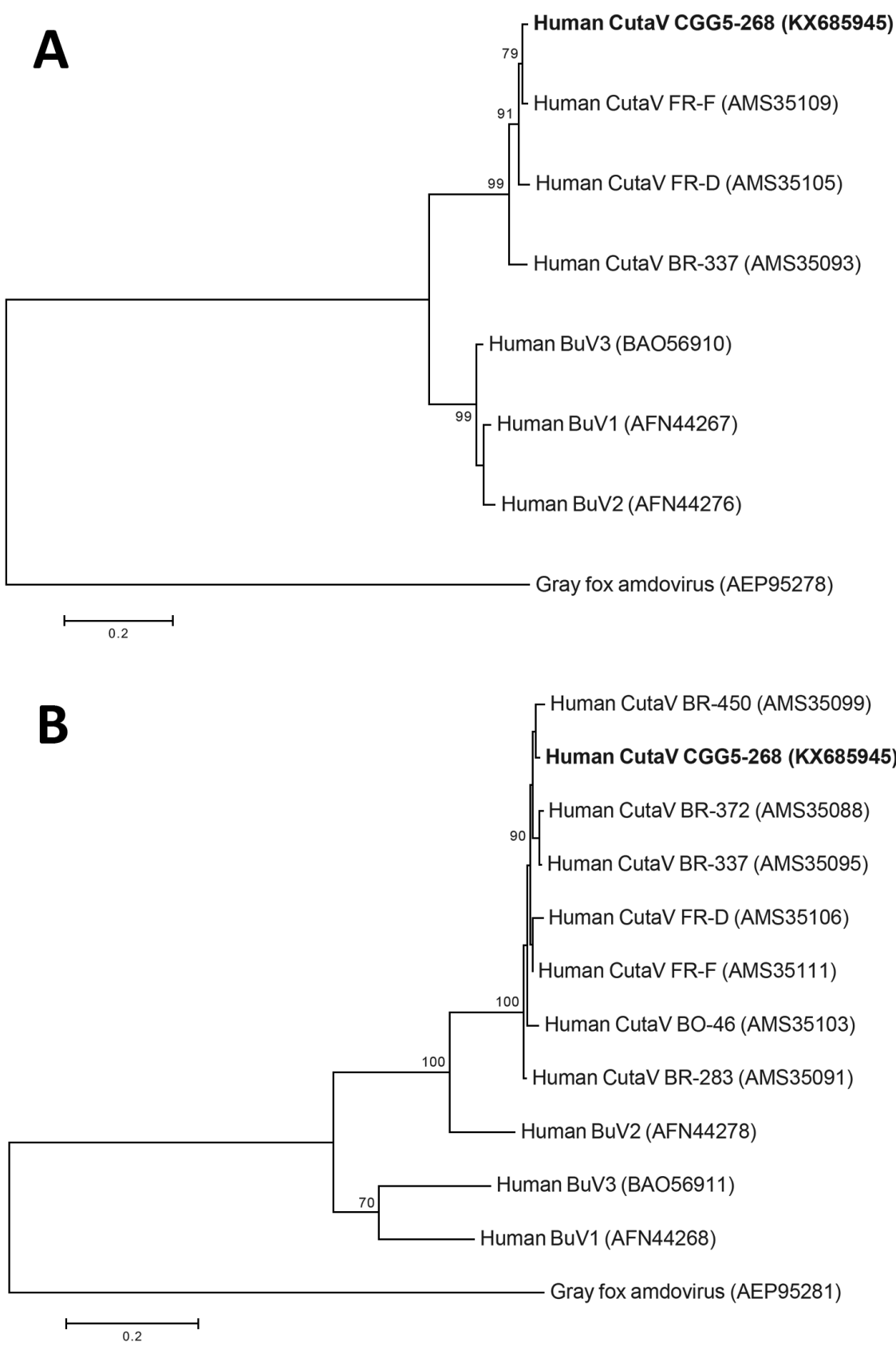

Figure. Phylogenetic analysis of human cutaviruses (CutaV) and bufaviruses (BuV) based on the full nonstructural protein $1(A)$ and viral protein 1 (B) amino acid sequences. The trees were constructed by the maximum-likelihood method with 100 bootstrap replicates. Gray fox amdovirus was used as an outgroup. Bold indicates novel CutaV strain (CGG5-268) from this study. Scale bars indicate amino acid substitutions per position.

\footnotetext{
99
}

Human BuV2 (AFN44276)

Gray fox amdovirus (AEP95278) 


\section{References}

1. Phan TG, Dreno B, da Costa AC, Li L, Orlandi P, Deng X, et al. A new protoparvovirus in human fecal samples and cutaneous $\mathrm{T}$ cell lymphomas (mycosis fungoides). Virology. 2016;496:299-305. http://dx.doi.org/10.1016/j.virol.2016.06.013

2. Altay A, Yahiro T, Bozdayi G, Matsumoto T, Sahin F, Ozkan S, et al. Bufavirus genotype 3 in Turkish children with severe diarrhoea. Clin Microbiol Infect. 2015;21:965.e1-4. http://dx.doi.org/10.1016/j.cmi.2015.06.006

3. Chieochansin T, Vutithanachot V, Theamboonlers A, Poovorawan Y. Bufavirus in fecal specimens of patients with and without diarrhea in Thailand. Arch Virol. 2015;160:1781-4. http://dx.doi.org/ 10.1007/s00705-015-2441-z

4. Phan TG, Vo NP, Bonkoungou IJO, Kapoor A, Barro N, O'Ryan M, et al. Acute diarrhea in West African children: diverse enteric viruses and a novel parvovirus genus. J Virol. 2012;86:11024-30. http://dx.doi.org/10.1128/JVI.01427-12

5. Smits SL, Schapendonk CME, van Beek J, Vennema H, Schürch AC, Schipper D, et al. New viruses in idiopathic human diarrhea cases, the Netherlands. Emerg Infect Dis. 2014;20:121822. http://dx.doi.org/10.3201/eid2007.140190

6. Yahiro T, Wangchuk S, Tshering K, Bandhari P, Zangmo S, Dorji T, et al. Novel human bufavirus genotype 3 in children with severe diarrhea, Bhutan. Emerg Infect Dis. 2014;20:1037-9. http://dx.doi.org/10.3201/eid2006.131430

7. Huang D-D, Wang W, Lu Q-B, Zhao J, Guo C-T, Wang H-Y, et al. Identification of bufavirus- 1 and bufavirus- 3 in feces of patients with acute diarrhea, China. Sci Rep. 2015;5:13272. http://dx.doi.org/10.1038/srep13272

8. Väisänen E, Kuisma I, Phan TG, Delwart E, Lappalainen M, Tarkka E, et al. Bufavirus in feces of patients with gastroenteritis, Finland. Emerg Infect Dis. 2014;20:1077-79. http://dx.doi.org/ 10.3201/eid2006.131674

9. Adamson-Small LA, Ignatovich IV, Laemmerhirt MG, Hobbs JA. Persistent parvovirus B19 infection in non-erythroid tissues: possible role in the inflammatory and disease process. Virus Res. 2014;190:8-16. http://dx.doi.org/10.1016/j.virusres.2014.06.017

10. Li W-X, Wei Y, Jiang Y, Liu Y-L, Ren L, Zhong Y-S, et al. Primary colonic melanoma presenting as ileocecal intussusception: case report and literature review. World J Gastroenterol. 2014; 20:9626-30.

Address for correspondence: Sarah Mollerup, Centre for GeoGenetics, Natural History Museum of Denmark, University of Copenhagen, Oester Voldgade 5-7, DK-1350 Copenhagen, Denmark; email: sarah.mollerup@snm.ku.dk

\section{Reoccurrence of Avian Influenza A(H5N2) Virus Clade 2.3.4.4 in Wild Birds, Alaska, USA, 2016}

\section{Dong-Hun Lee, Mia K. Torchetti, Mary Lea Killian, Thomas J. DeLiberto, David E. Swayne}

Author affiliations: US Department of Agriculture, Athens, Georgia, USA (D.-H. Lee, D.E. Swayne); US Department of Agriculture,
Ames, lowa, USA (M.K. Torchetti, M.L. Killian); US Department of Agriculture, Fort Collins, Colorado, USA (T.J. DeLiberto)

DOI: http://dx.doi.org/10.3201/eid2302.161616

We report reoccurrence of highly pathogenic avian influenza $\mathrm{A}(\mathrm{H} 5 \mathrm{~N} 2)$ virus clade 2.3.4.4 in a wild mallard in Alaska, USA, in August 2016. Identification of this virus in a migratory species confirms low-frequency persistence in North America and the potential for re-dissemination of the virus during the 2016 fall migration.

$\mathrm{H}$ istorically, apparently effective geographic barriers (Bering and Chukchi Seas of the North Pacific Ocean) appeared to limit dissemination of Asian-origin, highly pathogenic avian influenza virus (HPAIV), such as influenza A(H5N1) virus A/goose/Guangdong/1/1996 (Gs/GD), between the Old and New Worlds (1). However, such barriers are incomplete; occasional spillovers of virus genes move from 1 gene pool to another (2). Asian-origin HPAIV H5N8 was identified in North America at the end of 2014 (3).

Novel HPAIVs H5N1, H5N2, and H5N8 emerged in late 2014 by reassortment with North American low pathogenicity avian influenza viruses (4). A novel reassortant $\mathrm{H} 5 \mathrm{~N} 2$ virus originating from Asian-origin $\mathrm{H} 5 \mathrm{~N} 8$ virus clade 2.3.4.4 and containing Eurasian polymerase basic 2, polymerase acidic, hemagglutinin, matrix, and nonstructural protein genes and North American lineage neuraminidase (NA), polymerase basic 1 (PB1), and nucleoprotein genes was identified on poultry farms in British Columbia, Canada, and in wild waterfowl in the northwestern United States. This virus subsequently predominated during influenza outbreaks in the United States in 2015.

During the boreal summer, birds from 6 continents (North America, South America, Asia, Africa, Australia, and Antarctica) fly to Alaska, USA, to breed. Thus, Alaska is a potentially major location for intercontinental virus transmission $(1,2)$. Recent data provide direct evidence for viral dispersal through Beringia $(5,6)$. Genetic evidence and waterfowl migratory patterns support the hypothesis that $\mathrm{H} 5$ virus clade 2.3.4.4 was introduced into North America through the Beringian Crucible by intercontinental associations with waterfowl (3). In addition, low pathogenicity avian influenza viruses were collected in Alaska before initial detection of H5 HPAIV clade 2.3.4.4, which contained genes that had recent common ancestry with reassortant $\mathrm{H} 5 \mathrm{~N} 2$ virus $\mathrm{PB} 1$, nucleoprotein, and NA (N2 subtype) genes and H5N1 virus PB1, polymerase acidic, NA (N1 subtype), and nonstructural protein genes of HPAIVs (7).

We report detection of an HPAIV H5N2 subtype from wild mallard sampled in Alaska during August 2016. Influenza A virus was detected in 48/188 dabbling duck 